\title{
Hereditary "pure" spastic paraplegia: a clinical and genetic study of 22 families
}

\author{
AE HARDING
}

From the MRC Clinical Genetics Unit, Institute of Child Health, London

SUMMARY In 22 families with the "pure" form of hereditary spastic paraplegia inheritance was autosomal dominant in 19 and autosomal recessive in three. Examination of intrafamilial correlation of age of onset in the dominant cases suggested that the disorder is genetically heterogeneous. Two forms of dominant hereditary spastic paraplegia were identified: one with an age of onset mostly below 35 years (type I), and the other with onset usually over 35 years (type II). In the type I cases, delay in walking was not infrequent and spasticity of the lower limbs was more marked than weakness. The disorder was very slowly progressive and was extremely variable in terms of severity. Sixteen per cent of the patients aged over 20 years were asymptomatic but clinically affected. In the type II group muscle weakness, urinary symptoms and sensory loss were more marked. This form of the disease evolved more rapidly. In the three families demonstrating autosomal recessive inheritance the clinical features were very similar to those of the dominant cases. Biological fitness of patients from both the dominant groups was not impaired and no definite evidence of new mutation was observed. A cumulative frequency curve of age of onset in the type I group was constructed which suggested that an asymptomatic child of an affected parent has a $20 \%$ chance of developing the disease at the age of 25 years; the risk is probably even less if the child is clinically normal.

The first clear description of hereditary spastic paraplegia (HSP) was that of Strümpell ${ }^{1}$ in 1880 although Seeligmüller ${ }^{2}$ had described a similar disorder four years previously. Strümpell reported two brothers in whom spastic paraplegia developed at the ages of 37 and 56 years. The reflexes were increased in the upper limbs but, apart from this, the abnormal findings were confined to the legs. Inheritance was probably autosomal dominant. Strümpell ${ }^{3}$ later described another similar family; the age of onset was in the third or fourth decade but the clinical features were almost identical to the first. Pratt ${ }^{4}$ commented "The concept of the disorder was originally clear and distinct ... these observations formed the ideal picture to which later published examples have on the whole regrettably refused to conform." Pratt refers to the profusion of descriptions of "hereditary spastic paraplegia plus" syndromes in the subsequent literature. These include spastic paraplegia in association with mental retardation and ichthyosis, ${ }^{5}$ pigmentary retinal degeneration, ${ }^{6}$ optic atrophy, ${ }^{7}$ amyotrophy, ${ }^{8}{ }^{9}$ ex-

Address for reprint requests: Department of Neurology, The Middlesex Hospital, Mortimer Street, London W1, UK.

Accepted 13 July 1981 trapyramidal features, ${ }^{10}$ sensory neuropathy, ${ }^{11}$ and ataxia and dysarthria. ${ }^{12}$ The pure form of hereditary spastic paraplegia (where the abnormal physical signs are virtually confined to those of a spastic paraplegia) has been said to be relatively rare. Bell and Carmichael ${ }^{13}$ could only find one family with the disease who had attended the (now) National Hospitals for Nervous Diseases over a 20 year period. Behan and Maia, ${ }^{14}$ in a study of six families, found that only seven of the $\mathbf{4 1}$ individuals known to be affected had been admitted to hospital for investigation. These authors suggested that the apparent rarity of the disorder was partly due to its relatively benign nature.

There have been no large scale personal surveys of patients with hereditary spastic paraplegia. Bell and Carmichael, ${ }^{13}$ Oszvath $^{15}$ and Holmes and Shaywitz ${ }^{16}$ have all reviewed previously published reports of families with the disease; these studies have yielded rather conflicting results with respect to the clinical and genetic features of the disorder. It has been suggested, on the basis of variation in age of onset, that the autosomal dominant form of HSP is genetically heterogeneous 31718 but this hypothesis has not been tested on a large series of patients with a carefully defined clinical syndrome. 
The definition of "pure" hereditary spastic paraplegia is difficult, and has varied from study to study. The families reviewed by Bell and Carmichael ${ }^{13}$ were clearly both clinically and genetically heterogeneous and included some with the associated features mentioned above, such as pigmentary retinal degeneration and mental retardation. Holmes and Shaywitz ${ }^{16}$ in a review of 104 stringently selected families, excluded any recorded cases from the category of "pure" HSP if any degree of ataxia was present. Mild clumsiness of the upper limbs has been described in members of families in which other individuals were not ataxic. ${ }^{19} 20$ It is difficult to be sure whether the clumsiness was due to early pyramidal involvement or if a true cerebellar component was present. It is probably reasonable therefore to include such families in the "pure" group. Bickerstaff ${ }^{21}$ commented on slight ataxia of gait in a few of his patients; again this is very difficult to assess in the presence of severe spasticity. Another source of confusion in terms of classification has been the finding of distal amyotrophy in some patients. Rhein ${ }^{22}$ felt that such cases were clinically and genetically distinct from pure HSP. This is clearly so in some families, such as those with the Troyer syndrome. ${ }^{9}$ Silver $^{8}$ and Holmes ${ }^{23}$ have also described families in which distal wasting, particularly of the hands, was a prominent and consistent feature. Dyck and Lambert ${ }^{24}$ reported two families in which the disorder resembled Charcot-MarieTooth disease, but the knee jerks were increased and the plantar responses extensor. Yet there are several kinships in the literature in which amyotrophy occurred in some affected individuals but not in others. 21 25-27 Attention was paid mostly to the presence of wasting or weakness of the small hand muscles, although distal wasting in the lower limbs did occur in some patients. Other members of these families only had signs of the "pure" disease. One possible interpretation is that distal amyotrophy may represent a late manifestation of the disorder.

This paper presents the clinical and genetic features of 22 families with the pure form of hereditary spastic paraplegia, which were seen by the author during a study of 200 families with various forms of hereditary ataxia and paraplegia.

\section{Patients and methods}

The 22 families were investigated as part of a clinical and genetic study of 200 families with progressive cerebellar and spinocerebellar degenerations. The latter families contained 234 index cases which were ascertained from the medical records departments of The National Hospitals for Nervous Diseases, The Hospital for Sick Children, Great Ormond Street, other London neurological centres and the records of the Friedreich's
Ataxia Group. Patients were included in the study if they had attended hospital during the period 1966-1980 and lived within a 50 mile radius of central London. Co-operative individuals were visited at home or in hospital by the author. A detailed history was taken which included details of first and second degree relatives. Full neurological and general examinations, twelve lead electrocardiography and urine testing were performed on the index cases. As many first degree relatives were seen and examined as possible.

The cases were initially divided into six major categories for the purpose of further analysis. These were as follows: (1) Friedreich's ataxia, as defined clinically by Tyrer $^{28}$ and other workers (90 families), (2) progressive ataxia developing within the first two decades associated with dysarthria and generally normal or increased tendon reflexes (20 families), (3) hereditary spastic paraplegia (29 families), (4) late onset cerebellar ataxia of autosomal dominant inheritance (11 families), (5) single cases of late onset cerebellar ataxia (36 families), and (6) other syndromes. The patients reported here are some of those in the third category. Patients were allocated to this category if the most prominent feature of their illness was a progressive spastic paraplegia. Seven of the 29 families contained individuals affected with complicated forms of hereditary spastic paraplegia. In two kindreds the disorder resembled peroneal muscular atrophy and was similar to that reported by Dyck and Lambert. ${ }^{24}$ Four other patients, from two sibships, had paraplegia associated with prominent ataxia, cerebellar dysarthria and intellectual impairment. Two of them (sisters) also had pigmentary macular degeneration as described by Kjellin. ${ }^{6}$ One single case had paraplegia, optic atrophy and wasting of the small hand muscles, and another had paraplegia associated with cerebellar ataxia and nystagmus. Members of the seventh family had recessively inherited paraplegia and, in addition, defective upward and lateral gaze.

Twenty-two families were considered to have the "pure" form of HSP. None had dysarthria, ocular signs or dementia. Patients were not excluded from this group if they had minimal ataxia in the upper limbs, or distal wasting of moderate degree if symptoms had been present for more than 10 years. There were 29 index cases; an additional 55 relatives were examined of which 27 were found to be affected. Individuals were not considered affected if they only had hyperreflexia; other signs such as extensor plantar responses, spasticity or pyramidal weakness were necessary for the diagnosis of HSP to be made. Thus a total of 56 patients were personally studied. A further 38 relatives were known to be affected by history.

The clinical features of three families are described in the Appendix for illustrative purposes. Their pedigrees are shown in fig 4 .

\section{Results}

GENETIC ASPECTS

In 18 families, inheritance was autosomal dominant. In another it was thought that dominant inheritance 
was likely but exact details were unavailable. In three families, there was no history of any similar disorder in the parents or offspring of affected individuals. Both parents were examined in one family and one in another; all were normal. The remaining parents were dead or unavailable for study. The mother and two children of one case had previously been examined elsewhere and found to be normal. None of the parents of these patients was consanguineous.

In the autosomal dominant families, the ratio of affected to unaffected offspring (aged over 60 years) of affected individuals (in generations where accurate information was available) was $76: 83$. This does not differ from the expected ratio of $1: 1\left(\chi^{2}=0.23\right.$, $p>0.05)$. The ratio of affected to unaffected was 55:83 if index cases were excluded $\left(\chi^{2}=5 \cdot 28\right.$, $\mathrm{p}<0.05)$. There were 56 affected males and 48 females; this difference is not statistically significant $\left(\chi^{2}=0.471, \mathrm{p}>0.05\right)$.

No examined affected individual had clinically normal parents although in one asymptomatic case (family 1), who had affected children and grandchildren, the only abnormal physical signs were the presence of increased tendon reflexes in the legs and extensor plantar responses. She also had mild urinary symptoms. In four other families there was a history of the disorder being transmitted to offspring by apparently unaffected individuals. Three of these were male and the other female.

The mean number of offspring of 15 index cases over the age of 30 years in the dominant families was $2.07 \pm 1.58$. The mean family size of all affected individuals (48), born in the last 50 years, was $2 \cdot 42 \pm 1.94$. Family size was compared with that of the general population, rather than that of normal sibs; the latter would have involved very small numbers and it cannot be assumed that the presence of a genetically determined disorder in a family only limits the number of offspring of affected members. The mean family size was estimated at $2 \cdot 15$ on the grounds that it has only varied between 2.0 and $2 \cdot 3$ since 1928 according to the Registrar General's statistics. Neither of the above values differed from 2.15 ( $t$ was 0.05 and $0.96, \mathrm{p}>0.05$ respectively).

\section{AGE OF ONSET: AUTOSOMAL DOMINANT} CASES

The mean age of onset in the dominant cases was $20.48 \pm 17.99$ years. Figure 1 is a histogram showing the distribution of age of onset. (These and subsequent data include information obtained by history, as well as in person.) There are a number of peaks but little evidence of bimodality. A correlation coefficient was calculated for age of onset between sib pairs; this was $0.82(p<0.001)$. Using the for-

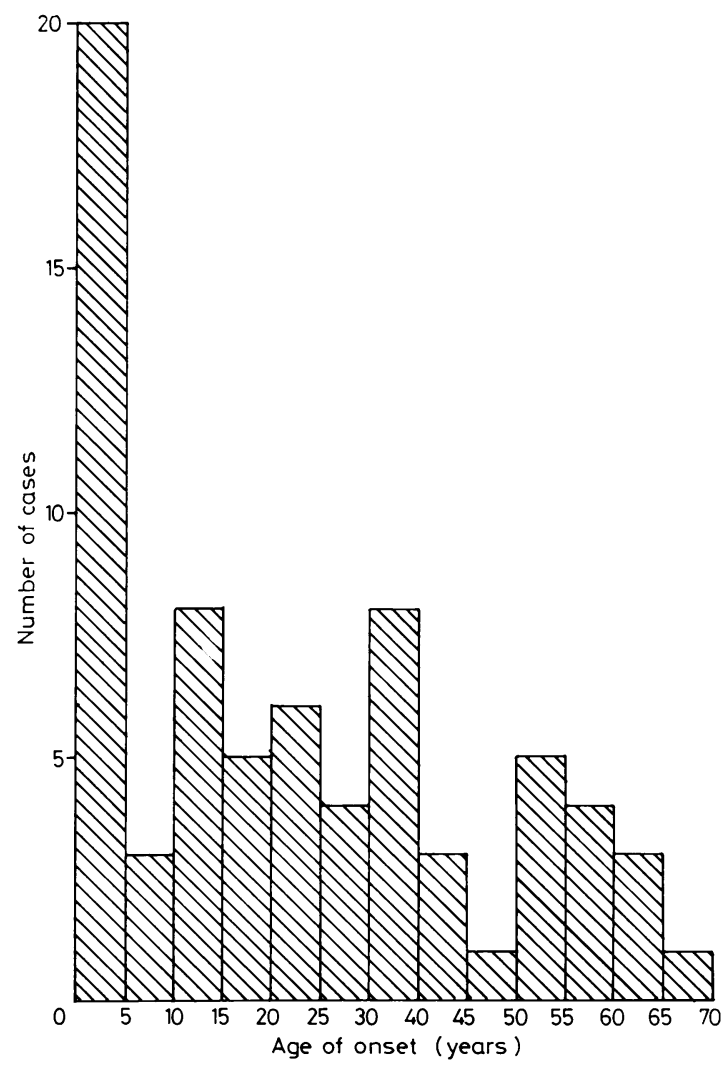

Fig 1 Histogram illustrating range of age of onset in autosomal dominant "pure" hereditary spastic paraplegia.

mula of Donner and Koval ${ }^{29}$ for correction of analysis of variance data, $r=0.60, p<0.001$. Both of these values suggest that the autosomal dominant form of HSP is caused by more than one gene (see discussion). Figure 2 is a correlation diagram of the sib-sib age of onset values, with the regression line drawn in. There is a suggestion of two clusters, one with an age of onset mainly above 35 years, and one below. The only markedly discordant values are contributed by a single patient.

Ten patients (four males and six females) were asymptomatic but clinically affected. Five of these (four males and one female) were less than 15 years old. The range of presenting symptoms of the rest is shown in table 1. Abnormality of gait was the initial complaint in the vast majority of cases, either noticed by the patients themselves or their relatives. In 18 patients information concerning early milestones was available; five had been late in walking. 


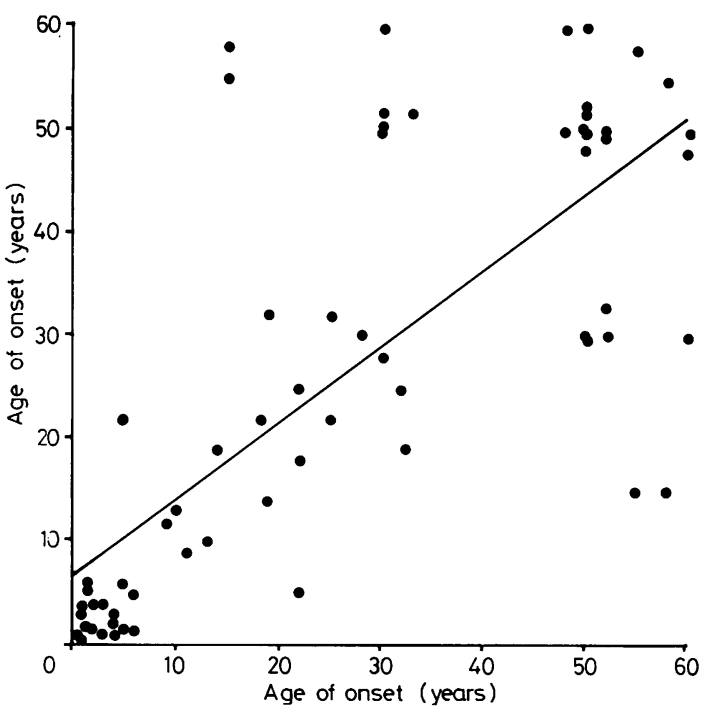

Fig 2 Diagram illustrating correlation between sib pairs for age of onset. The regression line is drawn in.
Table 1 Hereditary spastic paraplegia: presenting symptoms

\begin{tabular}{lcr}
\hline & Number of cases & $\%$ \\
\hline Abnormal gait & 22 & $43 \cdot 1$ \\
Difficulty walking & 16 & $31 \cdot 4$ \\
Stiffness of legs & 3 & $5 \cdot 9$ \\
Poor athletic performance & 1 & $2 \cdot 0$ \\
None & 9 & $17 \cdot 6$ \\
\hline
\end{tabular}

CLINICAL FEATURES: AUTOSOMAL

DOMINANT CASES

The incidence of various clinical features in these patients is shown in table 2 . These have been analysed for the total number of dominant cases and also with the families divided into two groups depending on whether age of onset was predominantly above (type II) or below (type I) 35 years. Fifteen families were in the early onset group (mean 13.49 \pm 12.25 years) and four had a later onset (mean $44.9 \pm 13.9$ years). The mean number of years since onset was $20 \cdot 0 \pm 14 \cdot 8$ years in the former and 17.22 $\pm 5 \cdot 36$ in the latter. It will be noted that in the early onset group, increase in muscle tone was more marked

Table 2 Autosomal dominant "pure" hereditary spastic paraplegia: clinical features

\begin{tabular}{|c|c|c|c|c|}
\hline & \multicolumn{3}{|c|}{ Number of cases } & \multirow[t]{2}{*}{$p(I v s I I)$} \\
\hline & Total (52) & Type I (43) & Type II (9) & \\
\hline Motor delay & $5 / 18$ & $5 / 18$ & 0 & ns \\
\hline Asymptomatic & 10 & 10 & 0 & ns \\
\hline Sex ratio $M: F$ & $27: 25$ & $21: 22$ & $6: 3$ & ns \\
\hline Mean years since onset & & $19 \cdot 6 \pm 14 \cdot 6$ & $17 \cdot 2 \pm 5 \cdot 4$ & ns* \\
\hline \multicolumn{5}{|l|}{ Upper limbs: } \\
\hline mild ataxia & 10 & 8 & 2 & ns \\
\hline pyramidal weakness & 2 & 1 & 1 & ns \\
\hline increased reflexes & 12 & 10 & 2 & ns \\
\hline distal wasting and weakness & 2 & 1 & 1 & ns \\
\hline \multicolumn{5}{|l|}{ Lower limbs: } \\
\hline increased tone: absent & 11 & 11 & 0 & ns \\
\hline mild & 17 & 16 & 1 & ns \\
\hline severe & 24 & 16 & 8 & $<0.01$ \\
\hline pyramidal weakness: absent & 15 & 15 & 0 & $<0.05$ \\
\hline mild & 19 & 18 & 1 & ns \\
\hline moderate & 16 & 9 & 7 & $<0.01$ \\
\hline severe & 1 & 1 & $\mathbf{0}$ & ns \\
\hline ankle jerks: absent & 7 & 6 & 1 & ns \\
\hline depressed & 1 & 1 & 0 & ns \\
\hline ankle clonus & 19 & 18 & 1 & ns \\
\hline Sensory loss: VBS & 12 & 5 & 7 & $<0.01$ \\
\hline JPS & 2 & 1 & 1 & ns \\
\hline Gait: normal & 8 & 8 & 0 & ns \\
\hline mildly spastic & 14 & 14 & $\mathbf{0}$ & ns \\
\hline moderately spastic & 12 & 9 & 3 & ns \\
\hline severely spastic & 17 & 11 & 6 & $<0.05$ \\
\hline Urinary symptoms & 23 & 15 & 8 & $<0.01$ \\
\hline Scoliosis & 1 & 1 & 0 & ns \\
\hline Pes cavus & 17 & 15 & 2 & ns \\
\hline
\end{tabular}

(Statistical comparisons by Fisher's exact test or* Student's $t$ test).

(VBS, JPS = vibration and joint position sense). 
than weakness. Pyramidal weakness was more frequent in the type II patients, and two-thirds of them had a severely spastic gait or were unable to walk, compared with only a quarter of the type I cases. In nearly $20 \%$ of the type I group, the gait was normal and a slightly higher proportion had normal muscle tone or power or both. This reflects the finding that asymptomatic individuals were only found in type I families. There was no difference in the incidence of upper limb hyperreflexia, ataxia, pyramidal weakness or distal wasting (of which the last three were infrequent) between the two groups. The same applies to pes cavus and depression or absence of the ankle jerks. Vibration sense was the most commonly abnormal sensory modality: joint position sense was impaired in only two patients and none had cutaneous sensory loss. Sensory loss was more frequent in the type II cases.

Urinary symptoms were experienced by 23 patients. Thirteen had urgency and six urinary frequency. Seven males had hesitancy and some were unable to micturate standing up. Sphincter disturbance was again more common in the type II group. None of the patients had bowel or sexual dysfunction.

In order to establish which clinical features tended to occur late in the course of the disease, the total number of dominant cases were divided into two groups, depending upon whether they had had symptoms for less, or more, than 10 years. It was not felt necessary to split the patients into types I and II for this purpose as both groups had had the disorder for roughly the same period of time, and the smaller numbers involved would make statistical analyses difficult. The incidence of various clinical features in the two categories defined above is shown in table 3 . The frequencies of moderately severe weakness in the lower limbs, upper limb hyperreflexia, sensory loss and urinary symptoms were higher in patients who had had the disease for more than 10 years. Distal wasting in the upper limbs occurred in two cases; the duration of the disease in them was 18 and 29 years.

Severity in this disorder is impossible to quantify. An attempt to compare degree of disability between types I and II and males and females was made by dividing the cases into three groups. These were (1) asymptomatic, (2) symptomatic but able to walk reasonably well and work, (3) unable to walk without aid or chairbound. The numbers of cases in each group, divided by sex and type, are shown in table 4 .

Table 3 Autosomal dominant "pure" hereditary spastic paraplegia: comparison of cases of short and long duration $(\%)$

\begin{tabular}{|c|c|c|c|}
\hline & $\begin{array}{l}\text { Duration less } \\
\text { than } 10 \text { years } \\
(12)\end{array}$ & $\begin{array}{l}\text { Duration more } \\
\text { than } 10 \text { years } \\
(31)\end{array}$ & $p^{*}$ \\
\hline \multicolumn{4}{|l|}{ Upper limbs: } \\
\hline ataxia & $3(25)$ & $8(25 \cdot 8)$ & ns \\
\hline hyperreflexia & 0 & $9(29 \cdot 0)$ & $\bumpeq 0.05$ \\
\hline pyramidal weakness & 0 & $2(6.4)$ & ns \\
\hline \multicolumn{4}{|l|}{$\begin{array}{l}\text { Lower limbs: } \\
\text { moderate or severe }\end{array}$} \\
\hline weakness & $1(8 \cdot 3)$ & $16(51 \cdot 6)$ & $<0.05$ \\
\hline sensory loss & 0 & $10(32 \cdot 2)$ & $<0.05$ \\
\hline $\begin{array}{l}\text { depressed or absent } \\
\text { ankle jerks }\end{array}$ & $3(25)$ & $3(9 \cdot 7)$ & ns \\
\hline Urinary symptoms & $2(16 \cdot 7)$ & $18(58 \cdot 1)$ & $<0.05$ \\
\hline
\end{tabular}

*Comparisons by Fisher's exact test.

The mean duration of disease was not different between males and females in type I (males 19.27 \pm 11.97 , females $20 \cdot 76 \pm 17.67$ years) or types $I$ and II $(t=0.07, \mathrm{p}>0.05)$. Statistical analyses on sex differences were not performed in the type II group as the numbers were so small. None of the other differences was statistically significant although it will be noted that there was a trend for the more severe type I cases to be male rather than female, and that over half of the type II cases were in group 3, as opposed to less than one quarter of the type I patients.

The mean age of onset in males was earlier than that of females in both groups of dominant HSP (type I: males $11.67 \pm 9 \cdot 3$, females $16 \cdot 70 \pm 16 \cdot 00$ years, $t=1.48, \mathrm{p}>0.05$; type II: males $42.85 \pm$ $13 \cdot 4$, females $48 \cdot 25 \pm 15 \cdot 28$ years, $t=0.90, \mathrm{p}>$ 0.05 ) although these differences were not significant. The mean ages of onset of offspring of affected males and females in type I were also similar (males $10.99 \pm 11 \cdot 35$, females $14.52 \pm 12.5$ years, $t=1.02$,

Table 4 Autosomal dominant "pure" hereditary spastic paraplegia: severity

\begin{tabular}{|c|c|c|c|c|c|c|}
\hline & \multicolumn{6}{|c|}{ Number of cases $(\%)$} \\
\hline & \multicolumn{3}{|l|}{ Type I } & \multicolumn{3}{|l|}{ Type II } \\
\hline & $\begin{array}{l}\text { Total } \\
(43)\end{array}$ & $\begin{array}{l}\text { Male } \\
(22)\end{array}$ & $\begin{array}{l}\text { Female } \\
(2 I)\end{array}$ & $\begin{array}{l}\text { Total } \\
(9)\end{array}$ & $\begin{array}{l}\text { Male } \\
(6)\end{array}$ & $\begin{array}{l}\text { Female } \\
(3)\end{array}$ \\
\hline Group I & $10(23 \cdot 2)$ & $3(14 \cdot 3)$ & $6(27 \cdot 3)$ & 0 & 0 & 0 \\
\hline Group II & $23(53 \cdot 5)$ & $11(52 \cdot 4)$ & $13(59 \cdot 1)$ & $4(44 \cdot 4)$ & $3(50)$ & $1(33 \cdot 3)$ \\
\hline Group III & $10(23 \cdot 2)$ & $7(33 \cdot 3)$ & $3(13 \cdot 6)$ & $5(55 \cdot 6)$ & $3(50)$ & $2(66 \cdot 7)$ \\
\hline
\end{tabular}

(None of these groupings are significantly different at the $5 \%$ level using Fisher's exact test). 
$p>0.05)$. This analysis was not performed for the type II group as the numbers were small.

Of the patients personally seen, six out of seven of the type I cases aged over 50 years were chairbound as opposed to five out of seven in the type II group. Only three patients (type I) out of 27 aged less than 35 years needed to use crutches or sticks in order to walk. The mean age of becoming chairbound in ten type I cases (on whom information was available) was $60.30 \pm 8.31$ years; this was significantly earlier than that of seven type II cases (71.71 \pm 6.65 years, $t=3.01, \mathrm{p}<0.01)$. However, the mean duration of the diseases at the time of losing the ability to walk independently was less in the type II group (type I: $38.3 \pm 12.99$, type II: $22.28 \pm$ 10.40 years, $t=2.71, \mathrm{p}<0.02$ ). Of the 20 patients who had died, the mean age of death in 10 type I patients was $66 \cdot 1 \pm 12 \cdot 1$ years compared to $74 \cdot 3 \pm$ 9.08 years in 10 type II cases $(t=1.71, \mathrm{p}>0.05)$.

Figure 3 is a cumulative frequency curve of age of onset for calculating risks to individuals of developing the disease at specified ages if they have an affected parent with the type I form of the disease. Again, small numbers prevented the construction of a similar curve for type II. Using Bayes' theorem ${ }^{31}$ probabilities of developing the disease in persons at risk were calculated, and those of their children. These are shown in table 5.

\section{AUTOSOMAL RECESSIVE "PURE" CASES}

There were only five personally seen patients from three families in this group. Reliable clinical information was obtained about two other affected relatives. The ages of onset in these individuals were as follows: 43 and 30 years; 4 and 7 years; 15 months and 4 years. These figures are suggestive of genetic heterogeneity in the recessive form of this disorder, although the numbers are too small to be confident about this. The clinical features of one of these families have been described (family 3 ). Upper limb ataxia and urinary symptoms only occurred in the family in which affected individuals had a later onset; the numbers are clearly far too small to stress this, or any other differences. The clinical features of the recessive cases were very similar to the dominant ones; there was no suggestion that they were more severely affected.

\section{OTHER FEATURES}

One boy was mildly mentally retarded; another girl had grand mal epilepsy. In one family (type I), all affected individuals were of short stature, had increased carrying angles and limitation of elbow movement, plus mild partial syndactyly of the second and third toes. Radiographs did not reveal any evidence of skeletal dysplasia such as hypochondro-

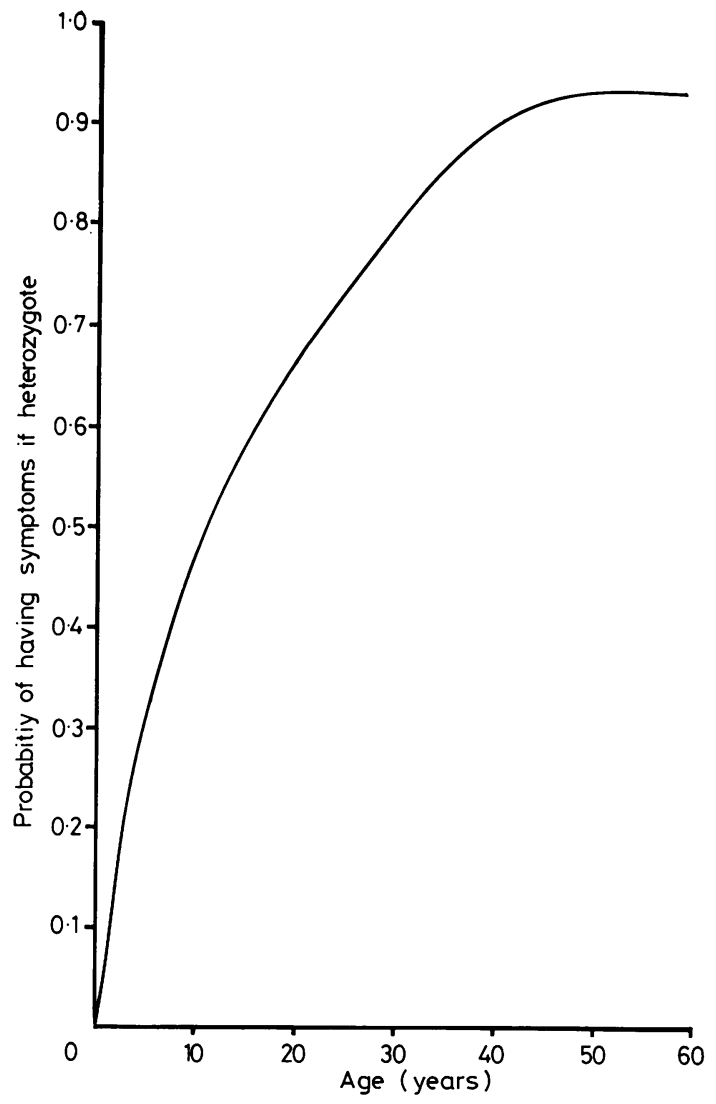

Fig 3 Curve (based on cumulative frequency for age of onset) for calculating risks of heterozygosity in relation to age of individuals with a $50 \%$ chance of developing type I autosomal dominant hereditary spastic paraplegia.

plasia. Three other patients had partial syndactyly of the second and third toes, which was marked in one.

Electrocardiographs (ECG) were performed in $\mathbf{4 0}$ cases. None showed any abnormalities which could not be explained on the basis of hypertension or

Table 5 Autosomal dominant "pure" hereditary spastic paraplegia type I: risks of heterozygosity based on cumulative age of onset curve

(The figures given are $x$, where risk $=1 / x$ )

\begin{tabular}{llcl}
\hline $\begin{array}{l}\text { Age of individual at } \\
\text { risk (ie affected } \\
\text { parent) }\end{array}$ & $\begin{array}{l}\text { Risk to } \\
\text { individual }\end{array}$ & Risk to child & $\begin{array}{l}\text { Risk to } \\
\text { grandchild }\end{array}$ \\
\hline 20 & & & \\
25 & $4 \cdot 1$ & $8 \cdot 2$ & - \\
30 & $4 \cdot 6$ & $9 \cdot 2$ & - \\
35 & $5 \cdot 4$ & $10 \cdot 8$ & - \\
40 & $7 \cdot 7$ & $15 \cdot 4$ & $30 \cdot 8$ \\
45 & $9 \cdot 0$ & $18 \cdot 0$ & $36 \cdot 0$ \\
\hline
\end{tabular}


ischaemic heart disease, apart from one 22-year-old male who had $\mathrm{T}$-wave inversion in some leads. Those were not present in other affected members of his family. None of the patients had known diabetes or glycosuria.

\section{NEUROPHYSIOLOGICAL FINDINGS}

Nerve conduction studies had been performed on 13 patients with the autosomal dominant form of "pure" spastic paraplegia (eight type I, three type II), and two with the recessive form. Mean median motor nerve conduction velocity (MNCV) was $57.0 \pm 5.51 \mathrm{~m} / \mathrm{s}(12$ patients) and mean peroneal MNCV was $49.75 \pm 3.40 \mathrm{~m} / \mathrm{s}$ (four patients). Neither of these values differ from those of normal controls. ${ }^{32}$ Sensory nerve action potentials (SAPs) had been measured in 12 patients. These were all normal. Electromyography (EMG) of the distal musculature in both upper and lower limbs showed signs of denervation in one patient. In another five patients EMG was normal.

\section{Discussion}

AUTOSOMAL DOMINANT "PURE", SPASTIC

PARAPLEGIA： EVIDENCE OF GENETIC

HETEROGENEITY

The range of age of onset in patients with autosomal dominant HSP was high. The sib-sib productmoment correlation coefficient, and the correlation coefficient obtained using the method of Donner and Koval ${ }^{29}$ both suggest that this disease is caused by more than one gene.$^{30}$ It is of interest that Bell and Carmichael $^{13}$ also reported high sib-sib correlation for age of onset in this disorder; the higher value they obtained $(0 \cdot 884)$ is probably due to less stringent selection of cases than that applied to the present study. Holmes and Shaywitz ${ }^{16}$ observed that the age of onset in dominant HSP occurred in the same decade within nearly two-thirds of families.

The data presented here would suggest that families with dominant HSP can be divided into two groups: those with an age of onset predominantly below, and those mainly above, 35 years. Admittedly there are a few instances of discordance. This is not surprising, considering how difficult it is to exactly date age of onset in a slowly progressive disorder. It is probably of importance that nearly all of the discordant values obtained (7/9) were from patients not personally seen and were thus subject to even more inaccuracy than the rest. From all the age of onset data, the discordance rate in the type I group was $9.2 \%$ and $19.05 \%$ in type II. It is quite possible that there is no exact delineation of the two groups, and that the distributions of age of onset overlap. This hypothesis would be supported by the histogram shown in fig 1 . The most reasonable way of dividing the two categories would seem to be by the use of $95 \%$ confidence limits of the means of age of onset: this gives an upper limit of 38.06 years in type I and a lower limit of $15 \cdot 72$ years in type IJ. The implications of this overlap, in relation to genetic counselling, will be discussed later. The classification suggested here would be in keeping with previously published reports, and confirm the original suggestion of Strümpell ${ }^{3}$ that HSP could be divided into two groups on the basis of age of onset. It is also of interest that families with late onset have been described less frequently than those with early onset; ${ }^{15}$ type I was nearly four times as common as type II in the present series.

The division of families proposed here is not only of theoretical interest. There are several differences between the two groups in terms of clinical features. There was a definite impression that the late onset form was more rapidly progressive than that of early onset, and the incidence of paresis of the lower limbs was higher in the former group. Although the type II patients lost the ability to walk on average later than the type I group, this was after a considerably shorter disease duration. There were no asymptomatic affected individuals amongst the type II cases, compared to $16 \%$ of the type I patients aged over 20 years. The incidence of sensory loss and urinary symptoms was also higher in the type II cases. Thurmon and Walker ${ }^{18}$ suggested that families with later onset dominant HSP had a higher incidence of sphincter disturbance. The presence of a more severe late-onset form of an autosomal dominant disorder would be in keeping with general genetic principles; if the situation were reversed, patients with a severe early onset disorder would be less likely to reproduce and so transmission of the mutant gene would be rare. It should be pointed out that the differences observed between the two groups are not due to disparity in disease duration; the mean duration was similar in both.

\section{CLINICAL FEATURES}

The frequency of delay in first walking observed in this series may well be an underestimate as most of the older patients seen had no knowledge of their early milestones. Motor delay has been mentioned in previous reports. ${ }^{1925}$ Some of the patients in this series had been diagnosed as having a "congenital spastic diplegia" or Little's disease. This is most likely to occur if the affected parent is asymptomatic; investigation of these infants should therefore include examination of both parents. It was of interest to the author that some of the asymptomatic patients, including a nurse, had obviously spastic gaits and yet denied symptoms. As the ratio of 
affected to unaffected individuals (excluding index cases) was less than unity in this series, it is quite possible that there were more asymptomatic affected individuals amongst those not personally seen.

Hereditary spastic paraplegia is not excessively rare, and there is a good case for examining first degree relatives as part of the investigative procedure in any patient with undiagnosed paraplegia, particularly if symptoms are relatively longstanding. This might avoid the use of invasive procedures; three of the patients seen in this study had been subjected to myelography. Stark and Moersch ${ }^{33}$ found that patients with HSP constituted $11.67 \%$ of a series of 60 patients with a "pure paraplegia" seen at the Mayo Clinic over a 20 year period. It is notable that relatives were not examined in two large follow-up studies of cases of undiagnosed paraplegia $; 3435$ this procedure might have increased diagnostic yield.

This study has confirmed the observation of other authors ${ }^{21} 36-38$ that the source of disability in HSP (particularly of early onset) is due to spasticity rather than weakness. Bickerstaff ${ }^{21}$ found weakness in only seven out of 43 individuals from one family. Some patients in this series had minimal weakness but great difficulty in walking as did those reported by Behan and Maia. ${ }^{14}$ Severe muscle weakness was rare, and tended to occur late in the evolution of the disease. Involvement of the upper limbs, in terms of hyperreflexia, was also a late feature.

The finding of sensory loss in a proportion of these patients, particularly the type II cases, is in keeping with some previous reports ${ }^{14}$ although Wilson ${ }^{37}$ stated that "sensory impairment is lacking" in HSP. The incidence of sensory loss increased with disease duration; this probably contributes to previous observations of lack of clinico-pathological correlation in relation to posterior column function. ${ }^{39}$ Nearly all necropsy cases will have had a long disease duration. The pathological findings should be correlated with the clinical features of patients of similar age, not a random sample with the disorder. It is also likely that considerable degeneration of the posterior columns is required before sensory loss is evident clinically. The finding of sensory loss in HSP is not incompatible with the observation of McLeod, Morgan and Reye and that in the current series, that sensory nerve conduction is normal. ${ }^{40}$ Behan and Maia $^{14}$ found that the peripheral nerves, dorsal roots and dorsal root ganglia were normal, and that the posterior column fibres near their point of entry to the spinal cord were relatively spared. Thus it appears that interruption of the sensory pathway occurs at a site proximal to the dorsal root ganglia; it is of interest that Thomas and colleagues ${ }^{41}$ have reported small or absent spinal evoked responses in some patients with HSP. The finding of absent ankle jerks in some patients in this series is also probably related to a central axonopathy rather than degeneration of the primary sensory neurone in toto; the same explanation has been offered for the loss of ankle jerks wihch occurs in clioquinol neurotoxicity. ${ }^{42}$

All the cases in this study who had more than mild distal amyotrophy, particularly in the upper limbs, had had symptoms for more than 15 years. The significance of mild distal wasting in the legs is difficult to assess. In one patient denervation of the distal musculature was confirmed electromyographically; motor nerve conduction was normal. These findings are in keeping with the occasional degeneration of anterior horn cells found at autopsy in HSP. ${ }^{43}$ It seems reasonable to suggest that distal amyotrophy is a variable late manifestation of the gene giving rise to autosomal dominant HSP; it is not concordant within families.

Urinary symptoms were frequent in this series, despite the claims of earlier authors. ${ }^{37} 3844$ Sphincter involvement was correlated with disease duration and, as has been mentioned, was more common in the type II group. Philip ${ }^{45}$ in the first description of HSP in Britain, noted that one of his patients suffered from urinary frequency. Cartlidge and Bone $^{46}$ described three male patients in whom urgency and frequency of micturition were prominent symptoms. Cystography revealed bladder sacculation and vesico-ureteric reflux in one case. Tests of other autonomic functions were normal. Bowel and sexual function were not impaired in any of the patients seen in this study; such impairment seems to be rare in HSP. Schwarz and $\mathrm{Liu}^{47}$ described a man with rectal urgency and occasional faecal incontinence in addition to urinary symptoms but abnormal sexual function has never been reported; one of Strümpell's patients fathered 29 children. ${ }^{1}$

Ataxia of the upper limbs was not common in the present series and was always mild. Its presence did not seem to be related to disease duration. The occurrence of ataxia is not surprising in view of the finding of spinocerebellar tract degeneration in about half of the necropsy cases of HSP44 47 The course and severity of the disease was similar to that observed by other authors. Although a considerable number of the patients studied were unable to participate in athletic pursuits, very few had had to give up work because of their disability. Only one of the patients studied (in the type I group) became unable to walk before the age of 50 years. Neither form of the disorder appeared to limit life expectancy.

Progression of HSP has been observed to be extremely slow; Bickerstaff ${ }^{21}$ commented that the degree of disability often seemed almost stationary after the 10 year period following the onset. Garland 
and Astley ${ }^{27}$ were impressed by the minor incapacity of their cases and the fact that all of them led full lives. Nevertheless, 13 of the 21 patients examined by Behan and $\mathrm{Maia}^{14}$ could only walk with the aid of sticks or were chairbound; some of these were aged under 30 years. Bell and Carmichael ${ }^{13}$ found the mean age of death in their dominant (more pure) cases to be $57.5 \pm 3.02$ years; the mean duration was $27.21 \pm 13.69$ years. The authors cited a still living patient who was said to have had the disease for 80 years.

\section{AUTOSOMAL RECESSIVE "PURE" SPASTIC PAR A PLEGIA}

In the two families where inheritance was thought to be autosomal recessive, and the age of onset was in the first decade, it is of interest that the clinical features and course of the disorder were not different from those of the type I dominant form of HSP. This similarity was also observed by Holmes and Shaywitz. ${ }^{16}$ In the other recessive family, onset was considerably later (in the fourth and fifth decades). It was not possible to examine the father of these two sibs but it is unlikely that he was affected; none of the type II dominant patients was asymptomatic. One of the affected individuals in this family was examined and found to be completely normal six years prior to the onset of symptoms. The later age of onset in this family, compared with the other two with recessive HSP, suggests that the recessive form of the disorder may also be genetically heterogeneous; with the small numbers of families involved it is impossible to be definite about this. Vernea and Symington $^{48}$ described two families with recessive, late onset spastic paraplegia; age of onset was concordant within the two sibships. The parents were first cousins in one family. It is of importance that there are no distinguishing clinical features between recessive and dominant HSP, as this means that is is difficult to make any assumptions concerning inheritance on the grounds of differences in either severity or physical findings.

\section{GENETIC CONSIDERATIONS}

HSP was initially thought to be "familial" (that is, autosomal recessive). ${ }^{37}$ Strümpell ${ }^{1}$ considered his cases to be familial but, on close examination, it appears that the patients' mother was affected. She was stated to be "ein wenig gelahmt" (a little paralysed). It is likely that a proportion of the subsequent reports of recessive pure HSP in fact describe unrecognised dominant cases. Parents or children or both have rarely been examined, only stated to be unaffected by history. Bickerstaff ${ }^{21}$ felt that one should "view such assertions of normality with suspicion", because of his finding of so many asymptomatic affected individuals. Five of the families in the present series were thought to have the recessive form of the disease prior to examination of the parents. Bell and Carmichael ${ }^{13}$ found a high proportion of recessive cases in their review, but the heterogeneity of their material makes this difficult to interpret. The rate of first cousin marriage amongst the parents of the recessive patients was only $5.4 \%$; this is relatively low for a rare disorder and would support the possibility that some of the cases were dominant. In Holmes and Shaywitz ${ }^{16}$ more carefully selected series the ratio of dominant: recessive families was $7: 3$.

This study has confirmed that the pure form of HSP is more commonly of autosomal dominant inheritance. The proportion of recessive families in the whole series was $14 \cdot 3 \%$ (excluding the family where precise details were lacking); this is considerably lower than that reported in the literature which has ranged from 30 to $45 \% \%^{13} 1516$

There were several instances in this series where an apparently unaffected (unexamined) individual had transmitted the dominant form of HSP to his offspring. The number of such cases was even greater prior to examination of some asymptomatic patients. Bickerstaff ${ }^{21}$ reported the presence of the disease in the offspring of a clinically normal parent; the clinical features in the child were, however, somewhat atypical. There was another possible "skip" in Bickerstaff's large dominant pedigree but the individual concerned was unavailable for examination. Garland and Astley ${ }^{27}$ also described one instance of incomplete penetrance but it is not clear whether or not this person was examined. Bone $e t a^{49}$ reported the occurrence of HSP in one of monozygotic twins from a family in which several members had the dominant form of the disease. The affected twin had a paraplegia, but she also had severe pyramidal weakness of the right arm and could not walk without crutches two years after the onset of symptoms. The distribution of weakness and the course in this patient make a diagnosis of HSP highly unlikely.

No families with overtly $X$-linked recessive inheritance were identified in this series. The only one in which this was possible was a kindred in which only two brothers were affected; it was considered rather unlikely as the mother of the two boys had two normal sons by different fathers from that of the affected boys, and also a normal brother. Inheritance was thought to be probably autosomal recessive in this family although it was unfortunately impossible to examine the father: dominant inheritance cannot therefore be absolutely excluded. The X-linked form of HSP seems to be extremely rare. Some of the families reported as such clearly 
did not have the pure form of the disease. Baar and Garland ${ }^{50}$ described a family in which the affected boys were "born crippled"; they were mentally retarded with microcephaly, spastic tetraparesis, nystagmus, dysarthria and athetosis. From the clinical description they could have suffered from the Lesch-Nyhan syndrome. In Johnston and McKusick's family a number of the affected males had dysarthria, nystagmus and optic atrophy. ${ }^{51}$ Thurmon et $a^{52}$ and Zatz et $a l^{53}$ have reported kindreds in which the uncomplicated form of the disorder occurred only in males and the pedigrees were compatible with $\mathrm{X}$-linked recessive inheritance. However, few of the carrier females were examined. Raggio et $a^{54}$ described a further similar family, but on examination of the pedigree it is clear that the disease was transmitted to a male through a supposedly unaffected father. Haldane ${ }^{55}$ suggested partial sex-linkage in recessive HSP but this idea was firmly refuted by Morton. ${ }^{56}$

In relation to $\mathrm{X}$-linkage, it is of interest to note that several authors have reported an excess of affected males in HSP;15 163757 the proportion was around $60 \%$ in both dominant and recessive groups. It seems unreasonable to attribute this male excess to the presence of $\mathrm{X}$-linked cases in view of the paucity of genuine X-linked pedigrees amongst published reports. Becker ${ }^{58}$ has suggested that there are two types of autosomal dominant HSP, in one of which expression of the gene is limited in females. There was a tendency in the current series for males to have an earlier age of onset, and be more disabled, than females, although these differences were not statistically significant. Also, in the type I dominant form of the disease, there was a tendency for more females to be asymptomatic than males. These findings would suggest a minor degree of sex limited expression of the gene in females and might explain the apparent $\mathrm{X}$-linkage in the pedigrees of Thurmon et al and $^{52}$ atz et al. ${ }^{53}$

The severity of the type I form of HSP in this series varied enormously, as is illustrated by the 75-year-old asymptomatic grandmother of a severely affected male in family 1 who had minimal pyramidal signs. This sort of variation makes examination of parents of single cases or affected sibs mandatory, particularly in genetic counselling. If this is not practical, it is possible to calculate empirical risks to children of affected individuals who have asymptomatic parents but affected sibs. The proportion of asymptomatic cases aged over 20 years in this series was $16 \%(4 / 25)$. Therefore the chance of two or more affected sibs having an asymptomatic parent is about $1 / 6$; risks to their children are $1 / 12$. In the type II group there were no asymptomatic cases so this situation does not arise.
It should be pointed out that neither in this study nor those previously reported were single cases of spastic paraplegia included. The distinction of genetic from acquired spastic paraplegia of early onset would be extremely difficult, as would ascertainment of such patients from hospital records. It is likely, therefore, that the true incidence of recessive HSP is considerably higher than that reported here. For example, if 16 pairs of heterozygotes for recessive HSP married and all produced two children, the ratio of sibships containing none affected:one affected:two affected would be 9:6:1. Thus in a population where mean family size is not much higher than two, the number of single cases of recessive HSP is likely to outnumber those of affected sib pairs by a factor of nearly six.

Counselling such single cases is difficult. It is possible that some of these patients do not represent autosomal recessive HSP, but have non-genetic disorders. Also, some may represent new dominant mutations. There was little evidence for new mutation in the present study, as the disease extended back over many generations if accurate information was available, and biological fitness was not impaired. A prospective study of single cases is needed to establish recurrence risk for sibs and offspring. Examination of their parents is of course essential.

It is hoped that the curve constructed giving probablities of developing the type I form of the disease at different ages (fig 3) will aid counselling of individuals at risk. This curve can only be used if the age of developing symptoms is below the age of 15 years in some members of the family concerned, because of the overlapping ranges of age of onset between the two forms of dominant HSP. There were insufficient numbers in the type II group to give a probability curve. Separation of the two types of dominant HSP means that it is possible to counsel lower risks of developing the disorder to children of parents at risk (if their family has the type I form) than at present. These risks are almost certainly even less if such children are clinically normal; unfortunately it is not known how long abnormal physical signs antedate the onset of symptoms in either form of the disease.

I wish to thank the following, who kindly allowed me to study their patients: Sir Roger Bannister; Professors J Marshall and PK Thomas; Drs EM Brett, PB Croft, CJ Earl, W Gooddy, PC GautierSmith, RAC Hughes, RS Kocen and J Wilson. Financial support from the Friedreich's Ataxia Group and the Medical Research Council is gratefully acknowledged. Dr M Baraitser and Professor CO Carter provided helpful discussion and Miss $P$ Goffron much administrative assistance. 


\section{Appendix}

Family 1 (fig 4)

I.2. This male was known to have had "the family walk". He died at the age of 90 years having been chairbound for 10 years prior to his death.

II.1. This man was observed to lift up his legs with his hands in order to climb steps. He was chairbound for five years before he died at the age of 69 years.

III.1. This 77-year-old man walked on his toes at the age of six years and was never able to play sports. He was still able to walk short distances.

III.4. This 75-year-old woman had no symptoms apart from occasional urgency of micturition. On examination she had mildly increased tone in the legs, brisk knee and ankle jerks and extensor plantar responses.

III.5. This 60 -year-old man was noted by his relatives to have a progressively abnormal gait from the age of 19 years.

IV.2. Male, died aged 41 years. He walked on his toes at the age of four years but was still ambulant at the time of his death.

IV.4. Female aged 51 years. She had never been athletic and had difficulty in running but no other symptoms.

IV.6. This 48-year-old woman had noticed a tendency to trip for as long as she could remember which had been mildly progressive. On examination she had mild pyramidal weakness and increased tone in the legs. Her tendon reflexes were all increased with ankle clonus and extensor plantar responses and she had a spastic gait.

IV.7. Male aged 46 years. He walked on his toes from the time of first walking but was relatively little disabled.

IV.8. This 45-year-old male tended to trip when aged 13 years. However, he had played sports at school and his gait was only noticeably abnormal to observers if he was tired.

IV.9. This 42-year-old female had no symptoms. On examination she had pathologically increased tendon reflexes in the legs with extensor plantar responses and a mildly spastic gait.

V.2. and V.8. These males, aged 25 and 14 years, both developed progressive difficulty in walking around puberty.

V.9. This girl, who was killed at the age of 20 years, had a lifelong tendency to turn her toes in when walking.

V.10. Male aged 13 years. He always walked differently from other children and was outrun by his younger brother. On examination he had a mild spastic paraparesis with insreased tendon reflexes, ankle clonus and extensor plantar responses. His gait was mildly abnormal.
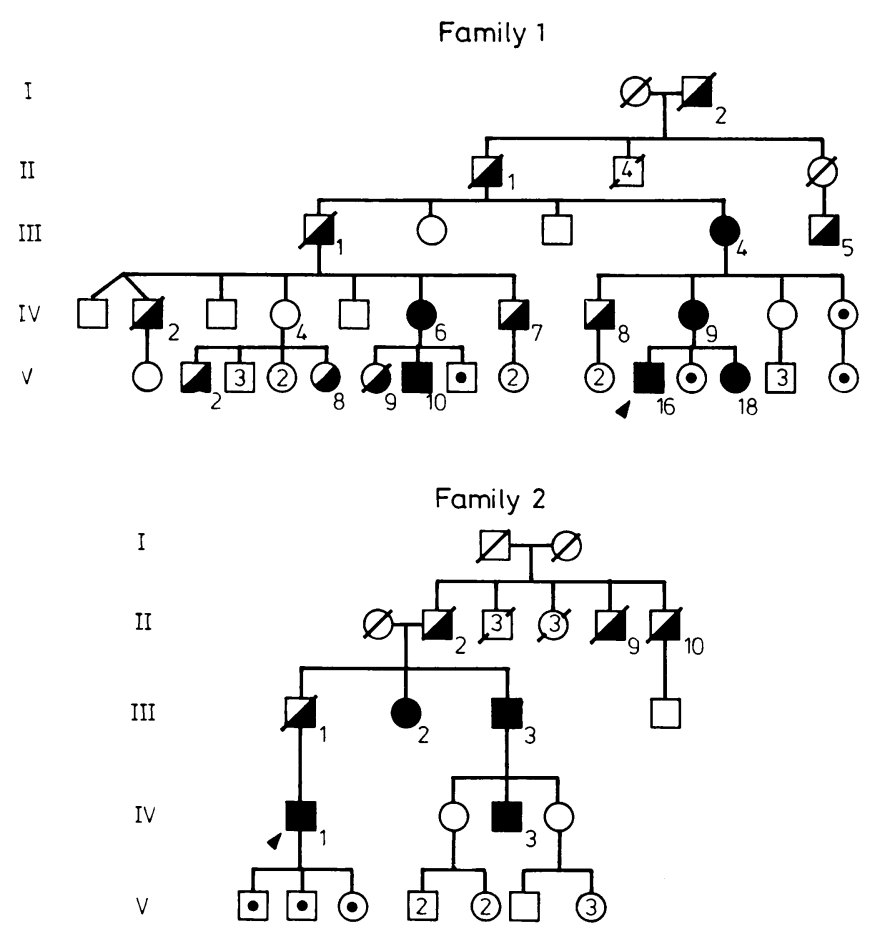

Family 3

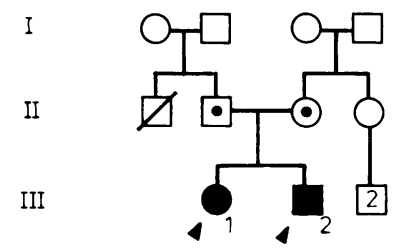

Male Female

(2) (2) Number of sibs

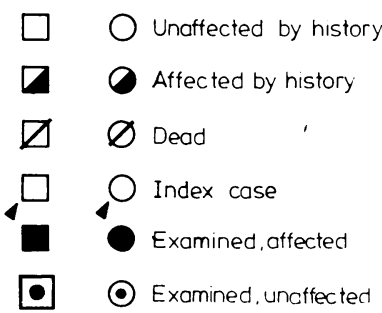

Fig 4 Pedigrees of families 1,2 and 3. 
V.16. (proband) This 22-year-old male developed a tendency to trip at the age of 7 years which had been mildly progressive. He had hesitancy of micturition. On examination, tone in the legs was markedly increased and there was mild pyramidal weakness and distal wasting. All the tendon reflexes were increased with ankle clonus and extensor plantar responses. He had a markedly spastic gait.

V.18. This 15-year-old girl had no symptoms. On examination there was mildly increased tone in the legs with pathologically brisk tendon reflexes and extensor plantar responses.

Family 2 (fig 4)

II.2,9,10 and III.1. These four males all died in the latter part of the eighth decade. They developed difficulty in walking and stiffness of the legs at ages ranging from 30 to 60 years, and were chairbound in their early seventies.

III.2. Female aged 78 years. She had had "arthritis" in the legs for many years and wore surgical boots from the age of 60 years. She had required amputation of some of her toes because of pain and foot deformity. She was just able to walk with a frame and had frequency of micturition with urgency incontinence. On examination she had mild weakness and wasting of the small hand muscles. There was a moderate spastic paraplegia and pes cavus. Her gait was markedly spastic.

III.3. This 74-year-old man began to "shuffle" at the age of 50 years and had had progressive difficulty in walking since. On examination he had moderately increased tone and pyramidal weakness in the legs with brisk knee jerks, absent ankle jerks and extensor plantar responses. Vibration sense was absent in the toes. He had a severely spastic gait and was just able to walk with a frame.

IV.1. Male aged 46 years. He began to trip easily when aged 33 years and had had progressive difficulty in walking since. He experienced urgency of micturition and occasional incontinence. On examination there was pyramidal weakness of the legs with marked spasticity, increased reflexes and extensor plantar responses. Vibration sense was reduced in the toes.

IV.3. This 41-year-old male noticed stiffness of his legs in cold weather at the age of 19 years; he was unable to run three years later. His disability had progressed, and he experienced hesitancy of micturition. On examination he had mild pyramidal weakness in the legs with marked spasticity. All his tendon reflexes were increased and the plantar responses extensor. There was mild pes cavus and his gait was moderately spastic.

Family 3 (fig 4)

III.1. This 15-year-old girl walked on her toes from the time of first walking at the age of 15 months. She had experienced minimal progression of her symptoms and had a tendency to trip on irregular surfaces. On examination the legs were mildly spastic with pyramidal weakness, brisk reflexes and extensor plantar responses. Her gait was mildly spastic.

III.2. This 11-year-old boy was noted to trip and walk on his toes at the age of five years. His disability had been very slowly progressive. The findings on examination were virtually identical to those of his sister.

\section{References}

${ }^{1}$ Strümpell A. Beiträge zur Pathologie des Rückenmarks. Arch Psychiatr Nervenkr 1880;10:676-717.

${ }^{2}$ Seeligmüller A. Sklerose der seitenstrange des Rückenmarks bei 4 kindern derselben Familie. Dtsch Med Wochenschr 1876;2:185-6.

${ }^{3}$ Strümpell A. Die primäre Seitenstrangsklerose (spastische Spinalparalyse). Dtsch $Z$ Nervenheilkunde 1904;27:291-339.

${ }^{4}$ Pratt RTC. The genetics of neurological disorders. Oxford University Press, 1967, p 44.

${ }^{5}$ Sjögren $T$, Larsson $T$. Oligophrenia in combination with congenital ichthyosis and spastic disorders: A clinical and genetic study. Acta Psychiatr Scand 1957;32, Supp. 113:1-112.

${ }^{6} \mathrm{Kjellin} \mathrm{K}$. Familial spastic paraplegia with amyotrophy, oligophrenia and central retinal degeneration. Arch Neurol 1959;1:133-40.

${ }^{7}$ Nyberg-Hansen R, Refsum S. Spastic paraparesis associated with optic atrophy in monozygotic twins. Acta Neurol Scand Suppl 51, 1972:261-3.

${ }^{8}$ Silver JR. Familial spastic paraplegia with amyotrophy of the hands. Ann Hum Genet 1966;30:69-75.

${ }^{9}$ Cross HE, McKusick VA. The Troyer syndrome. A recessive form of spastic paraplegia with distal muscle wasting. Arch Neurol 1967;16:473-85.

${ }^{10}$ Dick AP, Stevenson CJ. Hereditary spastic paraplegia: report of a family with associated extrapyramidal signs. Lancet 1953; i:921-3.

11 Cavanagh NPC, Eames RA, Galvin RJ, Brett EM, Kelly RE. Hereditary sensory neuropathy with spastic paraplegia. Brain 1979;102:79-94.

12 van Beusekom GT, Staal A, Went LN. A family with hereditary spastic ataxia. Acta Neurol Scand 1965; 41 :97-119.

13 Bell J, Carmichael EA. On hereditary ataxia and spastic paraplegia. Treasury Hum Inherit, Vol IV, Part III, 1939;141-281.

14 Behan WMH, Maia M. Strümpell's familial spastic paraplegia: genetics and neuropathology. J Neurol Neurosurg Psychiatry 1974;37:8-20.

15 Ozsvath K. Paralysis spinalis spastica familiaris. Dtsch Z Nerv 1968;193:287-323.

${ }^{16}$ Holmes GL, Shaywitz BA. Strümpell's pure familial spastic paraplegia: case study and review of the literature. J Neurol Neurosurg Psychiatry 1977;40: 1003-8.

${ }^{17}$ Haldane JBS. The relative importance of principal and modifying genes in determining some human diseases. J Genet $1941 ; 41: 149-57$.

18 Thurmon TF, Walker BA. Two distinct types of autosomal dominant spastic paraplegia. Birth Defects 
Original Article Series 1971:7;216-8.

19 Price GE. Familial lateral sclerosis (spastic paralysis). J Nerv Ment Dis 1939;90:51-5.

${ }^{20}$ Roe PF. Hereditary spastic paraplegia. $J$ Neurol Neurosurg Psychiatry 1963;26:516-9.

${ }^{21}$ Bickerstaff ER. Hereditary spastic paraplegia. $J$ Neurol Neurosurg Psychiatry 1950;13:134-45.

${ }^{2 \cdot 2}$ Rhein JHW. Family spastic paralysis. J Nerv Ment Dis 1916;44:115-44, 224-42.

${ }^{23}$ Holmes G. Family spastic paralysis associated with amyotrophy. Rev Neurol Psychiatry 1905;3:256-63.

${ }^{24}$ Dyck PJ, Lambert EH. Lower motor and primary sensory neuron diseases with peroneal muscular atrophy. II Neurologic, genetic and electrophysiologic findings in various neuronal degenerations. Arch Neurol 1968;18:619-25.

${ }^{25}$ Gee S. Hereditary infantile spastic paraplegia. St Barthol Hosp Rep 1889;25:81-3.

${ }^{26}$ Ormerod JA. An unusual form of family paralysis. Lancet 1904; ; :17-18.

${ }^{27}$ Garland HG, Astley CE. Hereditary spastic paraplegia with amyotrophy and pes cavus. J Neurol Neurosurg Psychiatry 1950;13:130-3.

${ }^{28}$ Tyrer JH. Friedreich's ataxia. In: Vinken PJ, Bruyn GW, eds. Handbook of Clinical Neurology. Amsterdam: North Holland Publishing Company, 1975; Vol $21: 319-64$

${ }^{29}$ Donner A, Koval JJ. The estimation of intraclass correlation in the analysis of family data. Biometrics 1980;36:19-25.

${ }^{30}$ Harris $\mathrm{H}$, Smith CAB. The sib-sib age of onset correlation among individuals suffering from a hereditary syndrome produced by more than one gene. Ann Eugenics 1947/9;14:309-18.

${ }^{31}$ Bayes T. An essay towards solving a problem in the doctrine of chances. Philos Trans $R$ Soc Lond 1763; 53:376-418.

${ }^{32}$ Thomas PK, Sears TA, Gilliatt RW. The range of conduction velocity in normal motor nerve fibres to the small muscles of the hand and foot. $J$ Neurol Neurosurg Psychiatry 1959;22:175-81.

${ }^{33}$ Stark FM, Moersch FP. Primary lateral sclerosis: A distinct clinical entity. J Nerv Ment Dis 1945;102: 332-7.

${ }^{34}$ Marshall J. Spastic paraplegia of middle age. Lancet 1955 ;i :643-6.

${ }^{35}$ Hübbe P, Dam AM. Spastic paraplegia of unknown origin. Acta Neurol Scand 1973;49:536-42.

${ }^{36}$ Jones E. Eight cases of hereditary spastic paraplegia. Rev Neurol Psychiatry 1907;5:98-106.

${ }^{37}$ Wilson SAK. In: Bruce AN, ed. Neurology. London: Arnold, 1940;781.

${ }^{38}$ Sutherland JM. Familial spastic paraplegia. In: Vinken PJ, Bruyn GW, eds. Handbook of Clinical Neurology. Amsterdam: North Holland Publishing Company, 1975;Vol 22:421-31.

${ }^{39}$ Newmark L. Klinischer Bericht über den siebenten Fall von spastischer Paraplegie in einer Familie und ergebuis der dritten Autopsie aus derselben Familie. Dtsch Z Nerven $1911 ; 42: 419-31$.

${ }^{40}$ McLeod JG, Morgan JA, Reye C. Electrophysiological studies in familial spastic paraplegia. $J$ Neurol Neurosurg Psychiatry 1977;40:611-5.

${ }^{41}$ Thomas PK, Jefferys JGR, Smith IS, Loulakakis D. Spinal somatosensory evoked potentials in hereditary spastic paraplegia. J Neurol Neurosurg Psychiatry $1981 ; 44: 243-6$.

${ }^{42}$ Baumgartner G, Gawel MJ, Kaeser HE, Pallis CA, Rose FC, Schaumburg HH, Thomas PK, Wadia NH. Neurotoxicity of halogenated hydroxyquinolones: clinical analysis of cases reported outside Japan. J Neurol Neurosurg Psychiatry 1979;42: 1073-83.

${ }^{43}$ Appel L, Van Bogaert L. Etudes sur la paraplégie spasmodique familiale. IV. Acta neurol psychiatrica belg 1952;52:129-40.

${ }^{44}$ Schwarz GA. Hereditary (familial) spastic paraplegia. Arch Neurol 1952;68:655-82.

${ }^{45}$ Philip RW. Primary spastic paralysis and pseudohypertrophic paralysis in different members of the same family, with probable heredity in both. Brain $1885 ; 8: 520-7$.

${ }^{46}$ Cartlidge NEF, Bone G. Sphincter involvement in hereditary spastic paraplegia. Neurology (Minneap) 1973;23:1160-3.

${ }^{47}$ Schwarz GA, Liu CN. Hereditary (familial) spastic paraplegia. Further clinical and pathologic observations. Arch Neurol 1956;75:144-62.

${ }^{48}$ Vernea J, Symington GR. The late form of pure familial spastic paraplegia. Proc Aust Assoc Neurol 1977;14: 37-41.

${ }^{49}$ Bone I, Johnson RH, Ferguson-Smith MA. Occurrence of familial spastic paraplegia in only one of monozygous twins. J Neurol Neurosurg Psychiatry 1976;39: 1129-33.

${ }^{50}$ Baar HS, Garland AM. Sex-linked spastic paraplegia. Am J Ment Def 1966;71:13-18.

${ }^{51}$ Johnston AW, McKusick VA. A sex-linked recessive form of spastic paraplegia. Am J Hum Genet 1962; 14:83-94.

${ }^{52}$ Thurmon TF, Walker BA, Scott CI, Abbott MH. Two kindreds with a sex-linked recessive form of spastic paraplegia. Birth Defects Original Article Series $1971 ; 7: 219-21$.

${ }^{53}$ Zatz M, Penha-Serrano, C, Otto PA. X-linked recessive type of pure spastic paraplegia in a large pedigree: absence of detectable linkage with $\mathrm{Xg}$. $J$ Med Genet 1976;13:217-22.

${ }^{54}$ Raggio JF, Thurmon TF, Anderson EE. X-linked hereditary spastic paraplegia. J La State Med Soc 1973;125:4-6.

${ }^{55}$ Haldane, JBS. The partial sex-linkage of recessive spastic paraplegia. J Genet $1941 ; 41: 141-7$.

${ }^{56}$ Morton NE. Further scoring types in sequential linkage tests, with a critical review of autosomal and partial sex linkage in man. Am J Hum Genet 1957; 9:55-75.

${ }^{57}$ Fontaine G, Dubois B, Farriaux JP, Maillard E. Une observation familiale de maladie de StrümpellLorrain. J Neurol Sci 1969;8:183-7.

${ }^{58}$ Becker PE. Humangenetik, Vol 5-1, Stuttgart: Verlag, $1966 ; 208-313$ 